\title{
CAPITAL INTELECTUAL: OS PRINCIPAIS MÉTODOS PARA MENSURAÇÃO E A SUA APLICABILIDADE
}

\section{INTELLECTUAL CAPITAL: THE MAIN METHODS FOR MEASURING AND ITS APPLICABILITY}

Data do recebimento do artigo: $9 / 03 / 2012$

Data do aceite do artigo: 12/09/2012

Data da publicação: $29 / 11 / 2012$

\author{
Carla Nunes Rodrigues ${ }^{1}$ \\ Graduada em Ciências Contábeis \\ Pontifícia da Universidade Católica de São Paulo \\ Fernando de Almeida Santos \\ Doutorado em Ciências Sociais \\ Pontifícia da Universidade Católica de São Paulo \\ Professor da Faculdade ENIAC
}

\section{RESUMO}

Esta pesquisa consiste em estudo bibliográfico sobre as formas de análise e mensuração contábil do capital intelectual corporativo. O objetivo é descrever os principais métodos existentes na literatura pesquisada, além de demonstrar sua aplicabilidade e evidenciar as vantagens e desvantagens para as empresas. $\mathrm{O}$ artigo destaca que apesar de ser relevante a necessidade da contabilidade mensurar os ativos intangíveis de forma que represente o real valor da empresa, há muitos desafios devido a subjetividade. Os diversos modelos de mensuração apresentados e comentados neste artigo evidenciam as tentativas empreendidas no sentido do desenvolvimento de critérios que auxiliem na gestão, na mensuração e no acompanhamento do capital intelectual.

Palavras-Chave: Ativo; Ativo Intangível; Capital Intelectual.

\begin{abstract}
This research consists in bibliographic researching about the ways of accounting measurement and analyzing corporate intellectual capital. The purpose is to describe the main of existing methods in investigated literature besides demonstrating its applicability and evidence the advantages and disadvantages for enterprises. The article highlights that despite of necessity to be relevant accounting measure intangible assets in order to represent the real value of the company, there are many challenges due to subjectivity. The various measurement models presented and discussed in this article highlight the attempts made towards the development of criteria to assist in the management, measurement and monitoring of intellectual capital.
\end{abstract}

Keywords: Active; Intangible Assets; Intellectual Capital.

\footnotetext{
1 Autor para correspondência: Pontifícia Universidade Católica de São Paulo - R. Monte Alegre, 984 - Perdizes, São Paulo - SP,Brasil - 05014-901
} 


\section{INTRODUÇÃO}

Mesmo as definições de Capital Intelectual sendo diferentes em alguns aspectos, há destaque sobre os seguintes aspectos como o fato de ser predominante a informação na cadeia de valor e de que o investimento em equipamentos. Destaca-se que a substituição de materiais e ativos físicos por conhecimento e a iniciativa em recompensar o trabalho baseado no conhecimento, preconizam a valorização dos talentos, a capacidade, a habilidade e as competências dos funcionários.

Devido ao alto grau de subjetividade e complexidade que envolve o assunto pode-se afirmar que não existe um consenso para o conceito de capital intelectual. Dessa forma, surge uma questão relevante: Quais são os principais métodos para mensuração do capital e como efetuar sua aplicabilidade?

O objetivo da pesquisa consiste em pesquisar e demonstrar os principais métodos para mensuração do capital intelectual e demonstrar sua aplicabilidade.

O trabalho, ainda destaca que, o Brasil para buscar a harmonização está internacional está passando por grandes mudanças legais na Contabilidade. Destacando-se as alterações na Lei $n^{\circ}$ 6.404/76, promovidas pelas Leis $n^{\circ}$ 11.638/07 e 11.941/09, e a elaboração e aprovação das Normas Brasileiras de Contabilidade, que exigem até uma nova estrutura para o balanço patrimonial. A aplicação da Lei $\mathrm{n}^{\circ}$ 11.638/07, para as companhias abertas e fechadas e sociedades de grande porte passou a ser uma exigência para os exercícios sociais com inícios a partir de $1^{\circ}$ de janeiro de 2008. As Normas Brasileiras de Contabilidade (NBCs) tem o objetivo de definir o tratamento contábil dos ativos intangíveis que não são abrangidos especificamente em outra norma.

A pesquisa realizada foi bibliográfica que abordou o conceito de capital intelectual e as suas normatizações contábeis, ao final é analisado e comparado os principais métodos de mensuração e a aplicabilidade do Capital Intelectual.

\section{CAPITAL INTELECTUAL}

\subsection{CONCEITOS}

Antes de conceituar capital intelectual é relevante compreender a importância deste conceito para o mercado empresarial, para economia e, consequentemente, para a sociedade atual. Portanto, para esta compreensão é apresentada uma citação de Drucker (1997) que afirma que a nova economia e o conhecimento não são apenas um recurso, ao lado dos tradicionais fatores da produção, que são trabalho, capital e terra; mas sim o único recurso significativo atualmente. Portanto, o fato de o conhecimento ter ser tornado o recurso, muito mais do que apenas um recurso, é o que tornar singular a nova sociedade. Drucker reconhece que o conhecimento é essencial, pois sem a terra, mão de obra e capital, nem mesmo o conhecimento pode produzir.

Portanto, nesta sociedade é muito importante conceituar capital intelectual.

A primeira matéria empregando o conceito do Capital Intelectual de que se tem informação foi a publicada por Thomas Stewart, na "Fortune", em 1994, com o título: "Your company's most valuable asset: intellectual capital”. Essa matéria, que serviu para alguns artigos acadêmicos nos Estados Unidos e no Brasil, abordava as primeiras experiências 
realizadas por algumas companhias para mensurar o seu Capital Intelectual, entre elas a Skandia.

O modelo de mensuração do Capital Intelectual da Skandia foi desenvolvido por um grupo de diretores que perceberam no início da década de 80 , de que o poder competitivo de uma empresa residia cada vez menos nos ativos contábeis tradicionais e cada vez mais em fatores subjetivos até então não mensurados, principalmente para eles, e para os demais, do setor de prestação de serviços baseados em conhecimento intensivo, como visualizar o valor real do setor de serviços era a questão.

Para Brooking (1996, p. 12-13), apud Antunes (2000, p.78) "o capital intelectual é uma combinação de ativos intangíveis, resultado de mudanças nas áreas da tecnologia da informação, mídias e comunicação, que trazem benefícios intangíveis para as empresas e capacita seu funcionamento".

No momento presente, os conceitos de Capital Intelectual diferem em alguns aspectos. Edvinsson e Malone (1998) empregam uma linguagem metafórica no intuito de melhor conceituar o Capital Intelectual. Comparando uma empresa a uma árvore, consideram a parte visível como tronco, galhos e folhas, a que está descrita em organogramas, nas demonstrações contábeis e em outros documentos, e a parte que se encontra abaixo da superfície no sistema de raízes, Capital Intelectual, que são os fatores dinâmicos ocultos que embasam a empresa visível formada por edifícios e produtos.

Os ativos intangíveis baseados em conhecimento, juntamente com os clientes e os fornecedores, constituem a base interna e externa da existência das organizações. Ao medir estes ativos intangíveis, a organização deve ter como objetivo principal aprender a conhecer realmente tudo sobre seu funcionamento (SVEIBY, 2000).

Objetivamente, Edvinsson (1998:58) coloca que o estudo do Capital Intelectual pode ser visto como a procura de maneiras para captar, elucidar e alavancar de forma sistemática as informações subjetivas, semi-ocultas, que se encontram escondidas nas Notas Explicativas.

Em relação às vantagens na mensuração do capital intelectual, Martin (2004) aponta as vantagens da mensuração do capital intelectual, entre elas destaca-se:

- - Aumento do potencial informativo da Contabilidade;

- - Redimensionamento patrimonial da entidade (clareza e adequação);

- - Canalização correta dos recursos para investimentos em capital humano e capital estrutural;

- - Facilitar a escolha do investidor;

- - Determinar de que maneira uma melhor gestão do conhecimento ajudará à empresa a ganhar ou a economizar dinheiro e ainda, evitar danos e injustiças que uma avaliação patrimonial incorreta traz, gerando lucros ou prejuízos indevidos.

\subsection{A IMPORTÂNCIA DO CAPITAL INTELECTUAL PARA A EMPRESA}

O talento dos funcionários, a eficácia de seus sistemas gerenciais, o caráter de seus relacionamentos com os clientes, que, juntos, constituem seu capital intelectual representam grande parte do valor da organização. 
Segundo EDVINSSON E MALONE (1998), os ativos intangíveis representam fatores extras contábeis que influenciam no valor de uma empresa e que conferem uma vantagem competitiva aos proprietários. Do ponto de vista de KARSTEN e BERNHARDT (2003, P.2), o grande responsável pela defasagem contábil (divergência entre o valor contábil e o valor de mercado da organização) é o conjunto dos recursos intelectuais que correspondem aos ativos mais valiosos encontrados nas empresas e que não são considerados.

O conhecimento tornou-se um recurso econômico proeminente. De acordo com Stewart (1997) considerado produtos econômicos, a informação e o conhecimento são mais importantes que os bens tangíveis valorizados, sobretudo na Era Industrial. Assim, ganha prioridade nas organizações nas organizações compreender como os ativos do conhecimento operam e se manifestam e entender o porquê de se gerenciar o capital intelectual, em face de pouca semelhança entre as empresas da Era da Informação e Era Industrial.

A mensuração do capital intelectual das empresas é muito importante porque é por meio da mensuração que as informações ocultas das empresas chegam até o ambiente e interessados externos, para explicar, por exemplo, o valor de uma entidade que na sua contabilidade vale 1 bilhão, mas o mercado esta disposto a pagar 5 bilhões. Essa diferença de 4 bilhões também conhecida como "goodwill" faz parte de um conjunto chamado capital intelectual, esse capital intelectual pode ser caracterizado por clientes, funcionários, localização, marcas e patentes e outros. Monobe (1986:51), observa que a primeira aparição do "Goodwill" foi vinculada à terra [ em 1571], e gradativamente foi sendo relacionado ao comércio, à personalidade dos proprietários, a processos industriais, a conexões financeiras e a staffs eficientes.Pode ser definido como um lucro anormal, além do esperado, sendo que a dificuldade reside na mensuração do valor atual dos benefícios futuros esperados.

Deve-se enfatizar que mensurar o capital intelectual possui vantagens do ponto de vista interno e externo. Seguem algumas das vantagens destacadas por Antunes (2000) e Brooking (1996, p.83).

- Do ponto de vista interno:

O conhecimento do capital intelectual identifica os recursos necessários em ativos intangíveis cujo desconhecimento, por vezes impede a consecução de um planejamento estabelecido.

O conhecimento detalhado que o modelo de avaliação dispõe sobre os clientes fornece uma visão bem mais abrangente das condições atuais e futuras da empresa relacionadas este foco.

- Do ponto de vista externo:

Os relatórios contendo os indicadores do capital intelectual são subsídios valiosos para os analistas e financiadores, pela projeção da futura capacidade da empresa gerar caixa.

Para os acionistas por sua vez, esses relatórios são de fundamental importância porque, fazendo uso das palavras de Edvinsson, "eles mostram o valor oculto das organizações", o qual não esta aparente nas demonstrações contábeis. Os acionistas podem ter igualmente a posição no momento e a visão do futuro, ou seja, as tendências apresentadas pela empresa.

Sua divulgação pode explicar a diferença entre o valor contábil e o valor de mercado de uma entidade, mesmo não sendo de forma objetiva.

Isso evidência a importância do capital intelectual proporcionando vantagens tanto para os usuários internos como os externos. O capital intelectual pode identificar para a empresa o seu potencial no presente e as perspectivas de benefícios futuros, contribuindo ainda mais para $\mathrm{o}$ crescimento da organização. 
Nas definições formuladas pelos pesquisadores citados, percebe-se a preocupação com o capital intelectual, tanto na academia como em ambientes empresariais do mudo todo. No Brasil, a ciência contábil vem buscando introduzir no seu ensino, o tema em questão, procurando produzir trabalhos e artigos científicos relativos ao Capital Intelectual.

\section{CAPITAL INTELECTUAL E AS NORMATIZAÇÕES RELATIVAS AO ATIVO}

\subsection{ATIVO}

Segundo a Lei 6.404/76 atualizada pela Lei 11.841/09, em seu art. 179, as contas serão classificadas do seguinte modo:

- no ativo circulante: as disponibilidades, os direitos realizáveis no curso do exercício social subseqüente e as aplicações de recursos em despesas do exercício seguinte;

- no ativo realizável a longo prazo: os direitos após o término do exercício seguinte, assim como os derivados de vendas, adiantamentos ou empréstimos a sociedade coligadas ou controladas (artigo 243), diretores, acionistas ou participantes no lucro da companhia, que não constituírem negócios usuais na exploração do objetivo da companhia;

- em Investimentos: as participações permanentes em outras sociedades e os direitos de qualquer natureza, não classificáveis no ativo circulante, e que não destinem à manutenção da atividade da companhia ou da empresa;

- No ativo Imobilizado: os direitos que tenham por objeto bens corpóreos destinados à manutenção das atividades da companhia ou da empresa ou exercidos com essa finalidade, inclusive os decorrentes de operações que transfiram à companhia os benefícios, riscos e controle desses bens;

- no intangível: os direitos que tenham por objeto bens incorpóreos destinados à manutenção da companhia ou exercidos com essa finalidade, inclusive o fundo de comércio adquirido.

\subsection{INTANGÍVEL}

Os intangíveis são ativos como outro qualquer, agregados de benefícios econômicos futuros sobre os quais uma dada entidade detém o controle e exclusividade na sua exploração, porém não são visivelmente identificados, logo intangíveis. O CPC 04 define ativo intangível como um ativo não monetário identificável sem substância física.

A Lei 6.404, de 15 de dezembro de 1976, não contemplava um grupo específico para evidenciar os Ativos Intangíveis, mas facultava o registro de alguns deles em outros grupos. Assim, gastos de implantação, gastos pré-operacionais, pesquisa e desenvolvimento, desenvolvimento de software eram registrados no grupo do Ativo Diferido e os gastos com direitos de propriedade e de ativos adquiridos separadamente no grupo de Ativo Imobilizado e aqueles que fizessem parte de uma combinação de negócios eram registrados no grupo de Ativo Investimento (FIPECAFI). O art. 179 da Lei ${ }^{\circ}$ 6404/76, em seu inciso VI, agora determina que seja classificado no intangível "os direitos que tenham por objeto bens incorpóreos destinados à manutenção da companhia ou exercidos com essa finalidade, inclusive o fundo de comércio adquirido". 
Um ativo intangível atende ao critério da identificação quando:

- for separável, ou em outras palavras, puder ser separado da entidade e vendido, transferido, licenciado, alugado ou trocado, individualmente ou junto com um contrato, ativo ou passivo relacionado, independentemente da intenção de uso pela entidade;

- ou resultar de direitos contratuais ou outros direitos legais, independentemente de tais direitos serem transferíveis ou separáveis da entidade ou de outros direitos e obrigações. Essa identificação é necessária para diferenciá-lo do Goodwill, que é um intangível não identificável.

O CPC 04 exige que a entidade reconheça um item como ativo intangível após ter demonstrado que esse item atendeu à definição e aos critérios de reconhecimento.

Considerados esses pontos iniciais, um intangível só deve ser reconhecido se:

- for provável que os benefícios econômicos futuros esperados atribuíveis ao ativo serão gerados em favor da entidade;

- e o custo do ativo possa ser mensurado com segurança. O ativo intangível deve ser mensurado pelo custo no momento do reconhecimento inicial.

\subsection{CAPITAL INTELECTUAL}

$\mathrm{Na}$ economia atual, marcada por mudanças aceleradas nos mercados, nas tecnologias e nas formas organizacionais, nota-se a importância do conhecimento como ferramenta para acompanhar este processo de inovação. No âmbito empresarial, o conhecimento pode ser traduzido como o Capital Intelectual, que se torna uma vantagem competitiva, uma fonte de geração de riqueza.

As principais mudanças ocorridas com a promulgação da lei atingem as Demonstrações Contábeis, especificamente a estrutura do Balanço Patrimonial, e o critério de avaliação das contas patrimoniais. Ressalta-se o artigo da Lei que trata diretamente da nova classificação do Ativo Intangível, anteriormente parte integrante do Ativo Imobilizado, que passa a ter categoria própria, tornando-se um subgrupo do Ativo Não Circulante.

A estrutura do ativo pela nova legislação deve contemplar o ativo não circulante, que contém os intangíveis. Nos intangíveis deve conter o capital intelectual.

Art. 178. No balanço contas serão classificadas segundo os elementos do patrimônio que registrem, e agrupadas de modo a facilitar o conhecimento e a análise da situação financeira da companhia.

$\S 1^{\circ}$ No ativo, as contas serão dispostas em ordem decrescente de grau de liquidez dos elementos nelas registrados, nos seguintes grupos:

II - ativo não circulante, composto por ativo realizável a longo prazo, investimentos, imobilizado e intangível.

Conforme a Lei fica nítida a preocupação do legislador em destacar os bens intangíveis, dando-lhe espaço próprio dentro da estrutura daquela considerada umas das principais demonstrações contábeis, o Balanço Patrimonial. Salienta-se dessa forma, a obrigatoriedade de se demonstrar estes bens incorpóreos, transparecendo seu valor dentro das entidades. Por ser obrigatória reforça a contabilidade a necessidade de a Contabilidade criar 
ferramentas de mensuração do Ativo Intangível, ressalta-se o Capital intelectual, que atualmente é considerado um recurso de extrema importância. Em decorrência da ausência de materialidade dos recursos intangíveis, surge uma discussão em torno da aplicação do princípio da objetividade, um dos pilares da prática contábil.

\section{OS PRINCIPAIS MÉTODOS DE MENSURAÇÃO E A APLICABILIDADE DO CAPITAL INTELECTUAL}

Em relação às vantagens na mensuração do capital intelectual, Martin (2004) aponta as vantagens da mensuração do capital intelectual, entre elas destaca-se:

- aumento no potencial informativo da Contabilidade;

- redimensionamento patrimonial da entidade (clareza e adequação);

- canalização correta dos recursos para investimentos em capital humano e capital estrutural;

- facilitar a escolha do investidor;

- determinar de que maneira uma melhor gestão do conhecimento ajudará à empresa a ganhar ou economizar dinheiro e ainda, evitar danos e injustiças que uma avaliação patrimonial incorreta traz, gerando lucros ou prejuízos indevidos.

Brooking (1996:83) enfatiza que o conhecimento do Capital Intelectual é uma fonte rica de informações sobre a organização em sua totalidade e, em particular, um instrumento valioso para os aspectos a seguir relacionados:

- confirmar a habilidade da organização para atingir objetivos;

- planificar a Pesquisa e Desenvolvimento;

- fornecer informações básicas aos programas de reengenharia;

- fornecer um foco para programas de educação organizacional e treinamento;

- analisar o valor da empresa;

- ampliar a memória organizacional.

Para que as empresas possam gerir eficazmente o capital intelectual da empresa e maximizar o seu potencial de criação de valor torna-se fundamental, não somente sua identificação e avaliação, mas também sua mensuração, que pode ser realizada por uma parcela de valor gerada pelo capital intelectual dentro da empresa, ou ainda, por meio das relações entre variáveis da empresa que conduzam a uma determinada quantia de capital intelectual.

\subsection{GOODWILL}

Monobe (1986:51), em sua tese de doutoramento intitulada Contribuição à mensuração e contabilização do Goodwill adquirido, observa que a primeira aparição do Goodwill foi vinculada a terra [em 1571], e gradativamente foi sendo relacionado ao comércio, à atividade industrial, à fidelidade da clientela, a localização privilegiada, à personalidade dos proprietários, a processos industriais, a conexões financeiras e a staffs eficientes. 
É sabido que a Contabilidade Financeira reconhece e contabiliza o Goodwill apenas quando ocorre a compre de uma empresa.

De acordo com as normas brasileiras o goodwill é denominado de super lucro por expectativa de rentabilidade futura, que é o valor da diferença entre o valor pago e o valor de mercado, enquanto que sob a ótica das normas internacionais e norte-americanas o goodwill é a diferença entre o valor pago e o valor justo dos ativos líquidos adquiridos, ou seja, é realizado o cortejamento dos ativos líquidos, procurando alocar o valor pago aos ativos. $\mathrm{O}$ valor residual, ou o valor não alocado a nenhum ativo é chamado de goodwill. A sua mensuração, e calculo de recuperabilidade se da pelo método holístico (Hoog, 2007).

Pelas normas norte-americanas e internacionais o goodwill é fundamentado unicamente na expectativa de um super lucro futuro, enquanto no Brasil é fundamentado da seguinte forma:

- diferença entre o valor de mercado dos ativos e passivos da investida e o seu valor contábil;

- expectativa de um super lucro futuro;

- direitos de exploração, concessão ou permissão delegada pelo poder público.

O valor do Goodwill de uma empresa, segundo observou Monobe (1986:62), seja em sua forma convencional, seja em sua forma definida como sinergístico, estará sempre relacionado com a capacidade de geração de lucros dessa empresa. Da mesma forma, os autores até então citados relacionam o Capital Intelectual à geração de lucros em longo prazo. Isso parece um tanto coerente com a definição de ativo adotada.

Ao se observarem os fatores que geram o Goodwill e os fatores que geram Capital Intelectual segundo Brooking (1996:17), podem ser identificados vários pontos em comum, conforme visto a seguir:

Fatores que geram o Goodwill:

- administração superior;

- organização ou gerente de vendas proeminentes;

- fraqueza na administração do competidor;

- propaganda eficaz;

- processos secretos de fabricação;

- boas relações com os empregados;

- crédito proeminente como resultado de uma sólida reputação;

- excelente treinamento para os empregados;

- alta posição perante a comunidade, conseguida por meio de ações filantrópicas e participação em atividades cívicas por parte dos administradores da empresa;

- desenvolvimento desfavorável nas operações do competidor;

- associações favoráveis com outra empresa;

- localização estratégica;

- descoberta de talentos ou recursos;

- condições favoráveis com relação aos impostos; 
- legislação favorável;

É relevante observar que os autores admitem a impossibilidade de listar todos os fatores e condições em virtude da própria natureza do Goodwill.

Fatores que geram o Capital Intelectual:

- conhecimentos, por parte do funcionário, do que representa seu trabalho para o objetivo global da companhia;

- funcionário tratado como um ativo raro;

- esforço da administração para alocar a pessoa certa na função certa, considerando suas habilidades;

- existência de oportunidade para desenvolvimento profissional e pessoal;

- avaliação do retorno sobre o investimento realizado em Pesquisa e Desenvolvimento (P\&D);

- identificação do Know-how gerado pela P\&D;

- identificação dos clientes recorrentes;

- existência de uma estratégia proativa para tratar a propriedade intelectual;

- mensuração do valor da marca;

- avaliação do retorno sobre o investimento realizado em canais de distribuição;

- sinergia entre os programas de treinamento e os objetivos corporativos;

- existência de uma infra-estrutura para ajudar os funcionários a desempenhar um bom trabalho;

- valorização das opiniões dos funcionários sobre aspectos de trabalho;

- participação dos funcionários na elaboração dos objetivos traçados;

- encorajamento dos funcionários para inovar;

- valorização da cultura organizacional.

No Brasil o valor do goodwill deve ser registrado em conta contábil separada do investimento. Entretanto, nas demonstrações contábeis consolidadas, o ágio com expectativa de lucros futuros deve ser evidenciado no grupo de investimentos, enquanto que o ágio fundamentado em diferença de valor de mercado deve ser ajustado nos ativos e passivos que lhe deram origem. De acordo com as normas internacionais e norte-americanas, o registro da aquisição é demonstrado nas demonstrações individuais da investidora pelo valor pago, sem que haja a segregação do goodwill. Contudo, nas demonstrações consolidadas o goodwill deve ser evidenciado no grupo de intangíveis.

A amortização do ágio era realizada de acordo com o fundamento que deu origem ao valor, atualmente, o novo padrão contábil brasileiro é baseado no padrão IFRS (International Financial Reporting Standards), que vigora apartir do exercício findo em 31de dezembro 2010. Por este padrão, de acordo com o IFRS 3 (R), ágio apurado não será amortizado e deverá ser testado anualmente por impairment test.

- Antes, era feito assim (apenas para registro):

- quando a diferença é proveniente do valor de mercado dos ativos líquidos, a amortização é realizada a medida que esses ativos forem sendo realizados por 
depreciação, amortização, exaustão, baixa por alienação ou perecimento dos bens ou do investimento;

- a expectativa de prejuízos futuros deve ser amortizada de acordo com a expectativa projetada, ou pela baixa por alienação ou perecimento do investimento, sendo que o prazo máximo não poderá exceder a dez anos;

- o deságio não deve ser amortizado, caso não esteja fundamentado em nenhuma das opções acima segundo as normas internacionais, o goodwill negativo deve ser reconhecido de imediato no resultado do exercício.

De acordo com as normas norte-americanas, o crédito diferido não é mais amortizado, o ajuste é realizado diretamente no resultado do exercício como um ganho extraordionário.

\subsection{SKANDIA}

Conforme o GRUPO SKANDIA (2004), a empresa representa o quarto maior grupo financeiro do mundo atuando na área de prestação de serviços financeiros e de seguros e o maior da Escandinávia. Opera em 23 países, organizado em três áreas estratégicas: LongTerm Savings, Asset Management e Property \& Casualty Insurance (Poupança de Longo Prazo, de ativos de propriedade e gestão e seguro contra acidentes). Tem como principal objetivo criar valor para seus acionistas por meio do foco em seus clientes, pela oferta de valor para seus acionistas por meio do foco em seus clientes, pela oferta de serviços inovativos, pelo aumento da produtividade e eficiência.

O modelo Skandia elaborado por Edvinsson chamou-se "Navegador Skandia". A principal argumentação do Navegador é a diferença entre os valores das empresas registrados nas demonstrações contábeis e os seus reais valores de mercado. O desafio para Edvinsson foi tornar visíveis estes valores para permitir a gestão sobre os mesmos. E o enfoque do modelo da Skandia parte do pressuposto de que o valor da empresa está integrado pelo capital financeiro e pelo Capital Intelectual, que o diagrama a seguir desmembra em blocos distintos entre sim, mas inter-relacionados.

No início dos trabalhos, em setembro de 1991, foi criada a função de Capital Intelectual (CI), a semelhança das demais áreas funcionais de uma organização, na Skandia Assurance \& Financial Service (AFS). A missão dessa nova função de Capital Intelectual pode ser resumida nos aspectos principais retratados a seguir (1998:38):

1) incentivar o crescimento e desenvolver o Capital Intelectual da empresa como um valor visível e permanente que complementasse o Balanço patrimonial;

2) estabelecer um elo entre a função de CI e as demais funções da empresa;

3) desenvolver novos instrumentos para a avaliação e medicação do Capital Intelectual;

4) implementar programas para acelerar a disseminação do conhecimento na organização.

Após o levantamento dos valores ocultos da AFS, foi elaborada uma relação com mais de 50 itens que possuíam valor e que não eram mencionados na contabilidade, decidiram simplificar devido a extensão da lista, sintetizando os itens e agrupando-os em dois grandes grupos: Capital Humano e Capital Estrutural.

Edvinsson (1998:39) relata que, em 1992, pôde divulgar internamente as três primeiras conclusões de sua equipe de trabalho, a saber: 
o Capital Intelectual constitui informação suplementar e não subordinada às informações financeiras;

o Capital Intelectual é um capital não financeiro, e representa a lacuna oculta entre o Valor de Mercado e o Valor Contábil;

o Capital Intelectual é um passivo e não um ativo.

A figura a seguir, elaborada pela equipe de Edvinsson, ilustra tais conclusões:

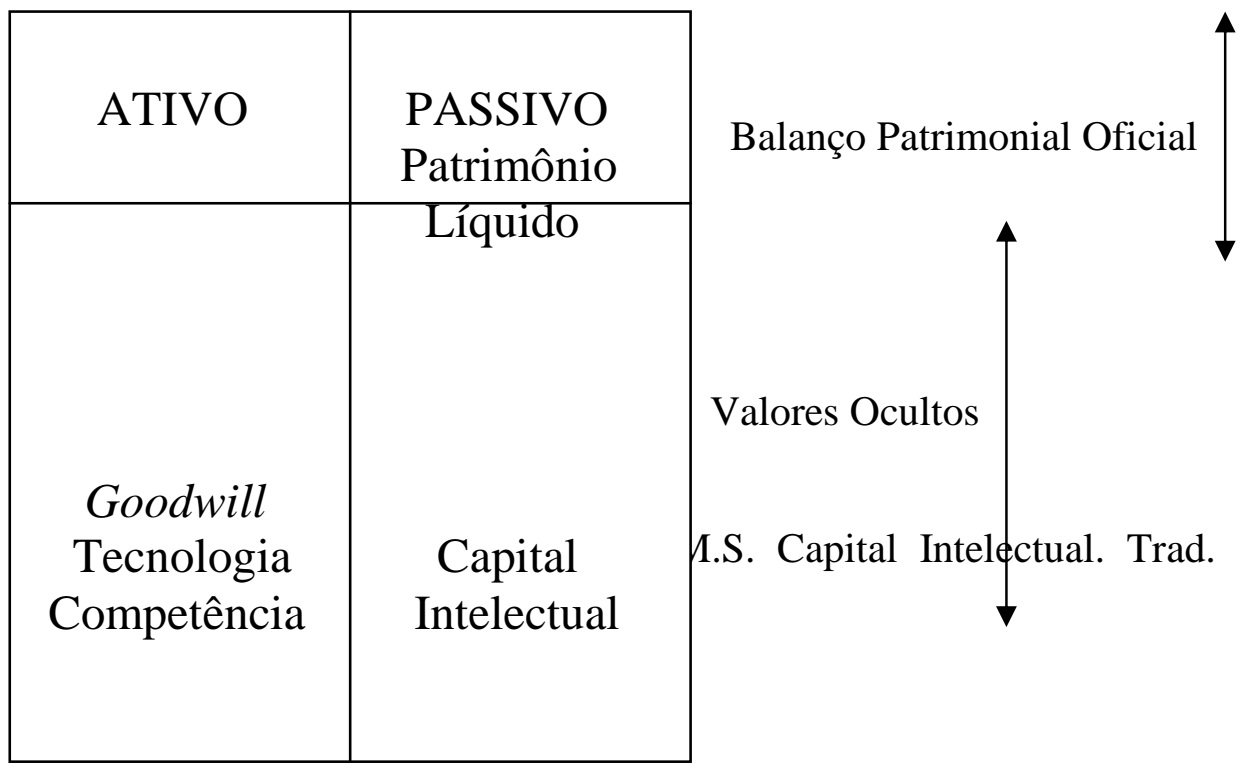

Conforme demonstrado por meio do esquema a seguir, pode-se verificar que os dois primeiros estágios representam a fórmula que os autores identificam como a do Capital Intelectual: Capital Intelectual = Valor de mercado - Valor Contábil $(\mathrm{CI}=\mathrm{VM}-\mathrm{VC})$. Extraídos os dois tipos de capital que representam a composição básica do Capital Intelectual (Capital Humano e Capital Estrutural), prosseguiu-se a uma sequência de mais duas subdivisões, resultando em mais dois subgrupos integrantes do Capital Estrutural.

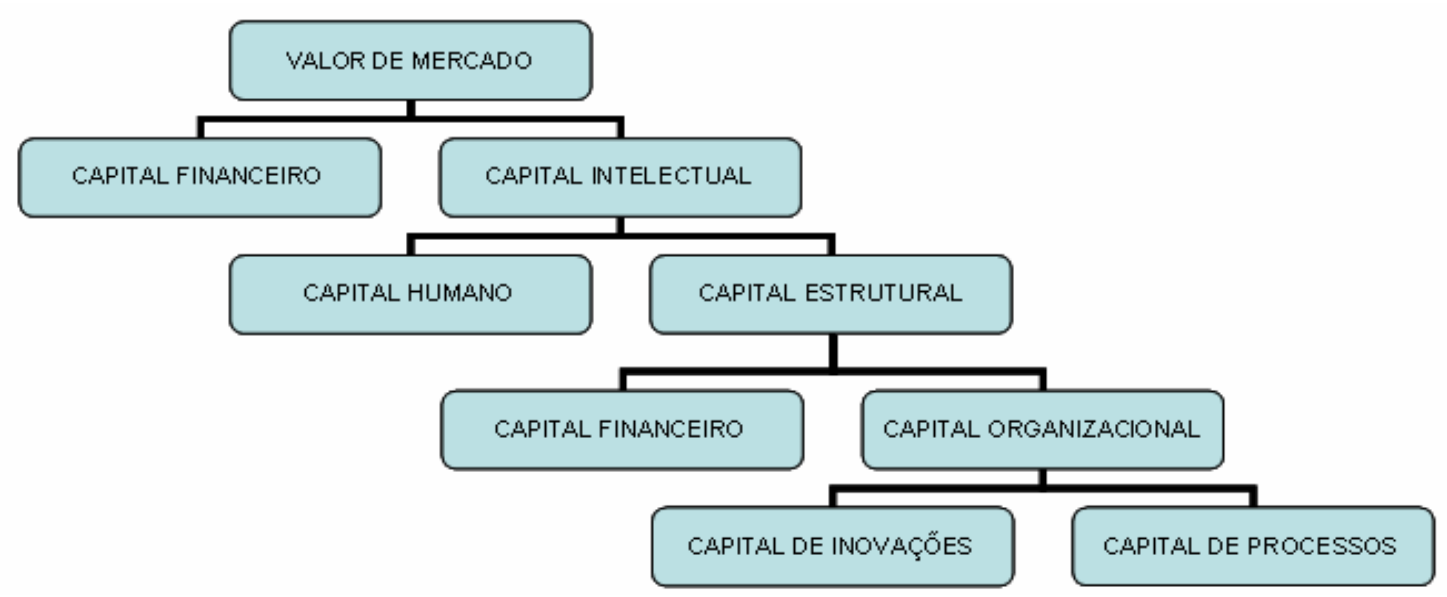

Figura 3 - Blocos Componentes do Valor das Organizações

Fonte: EDVINSSON(1998) apud ARNOST e GIL e NEUMAN (2003)

O Navegador da Skandia evidencia os fatores ocultos (Capital Intelectual) que sustentam os empreendimentos e que estão divididos em dois grupos distintos: 
Capital Humano - funcionários e seus conhecimentos, habilidades e poder de inovação, cultura, valores internos, entre outras características emanadas dessa estrutura humana.

Capital Estrutural - instalações e equipamentos industriais, equipamentos de informática e pela estrutura que estabelece a lógica dos processos (softwares) e de resultados (informações) ambos contidos em banco de dados, patentes e marcas.

Tal proposta determina que sejam estabelecidos vários índices e indicadores que serão agrupados nas seguintes áreas: Foco Financeiro; Foco nos clientes; Foco nos processos; Foco na renovação e desenvolvimento; e Foco humano.

O modelo, intitulado Navegador Skandia, apresenta certos valores de sucessos identificados pela equipe da empresa, que deveriam ser maximizados e incorporados à estratégia organizacional. Antunes (2000, p.97) explica que estes fatores foram agrupados em cinco áreas distintas de foco: financeiro, de clientes, de processo, de renovação e desenvolvimento e humano, que são representadas no Navegador Skandia na forma evidenciada na Figura 4.

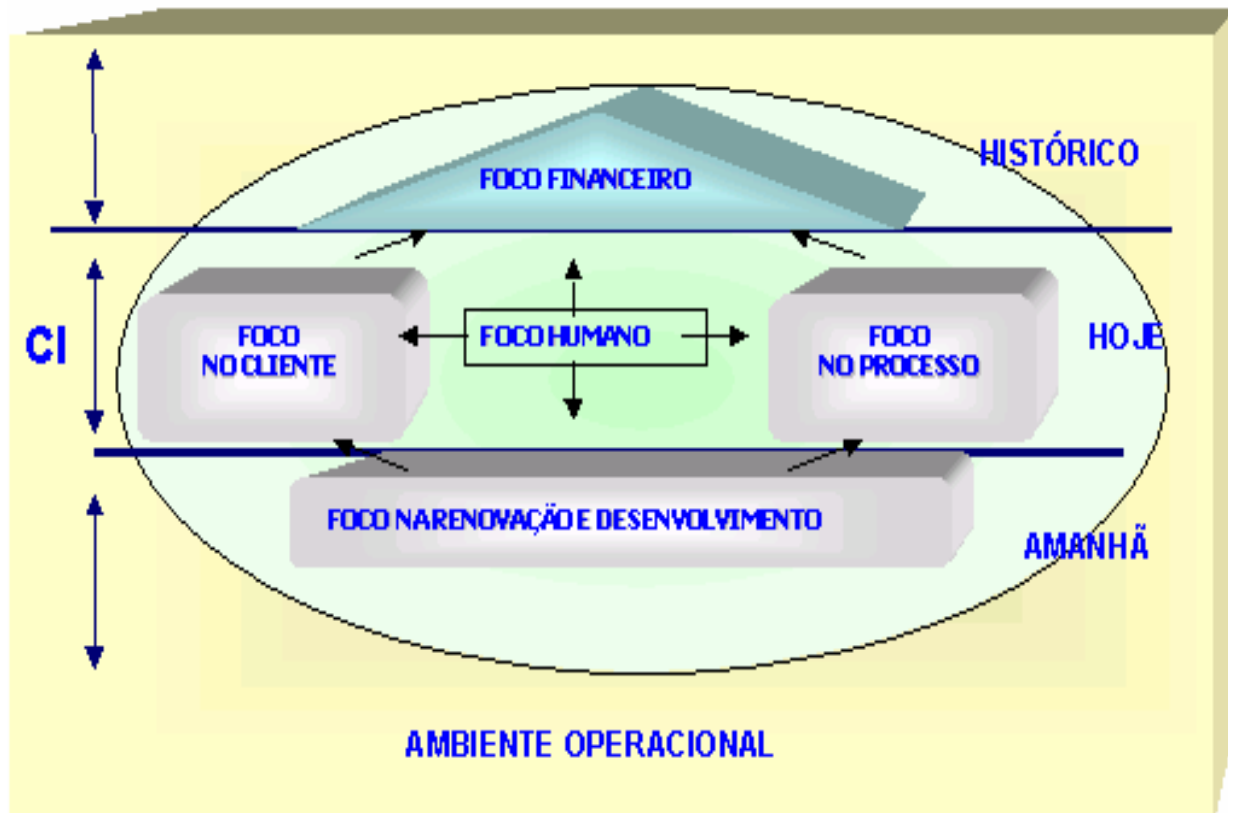

Figura 4 - Navegador Skandia

Fonte: EDVINSSON (1998) apud ARNOST e GIL e NEUMAN (2003)

Neste modelo apresenta-se:

- Foco financeiro: como o passado da entidade, o balanço patrimonial;

- Foco no cliente e foco no processo: visualiza-se o presente e as atividades da entidade, podendo-se destacar o Capital Intelectual e o Capital Estrutural;

- Renovação e desenvolvimento, a outra parte do Capital Estrutural, voltada para o futuro, onde se mede a eficiência de como a renovação de entidade está ocorrendo, sendo nos seus processos, no treinamento dos empregados e outras ações estratégicas;

- Foco humano: o centro e "alma" da entidade, seu coração, a inteligência, que como única força ativa na organização, alcança todas as outras regiões do Capital Intelectual. 


\subsection{NAVEGADOR DO CAPITAL INTELECTUAL - MODELO STEWART}

A figura 5 ilustra o navegador do capital intelectual proposto por Stewart (1998) a uma empresa fictícia, utilizando uma medida geral denominada de Razão Valor de Mercado/Valor Contábil, e três indicadores para cada um dos itens do capital humano, estrutural e do cliente.

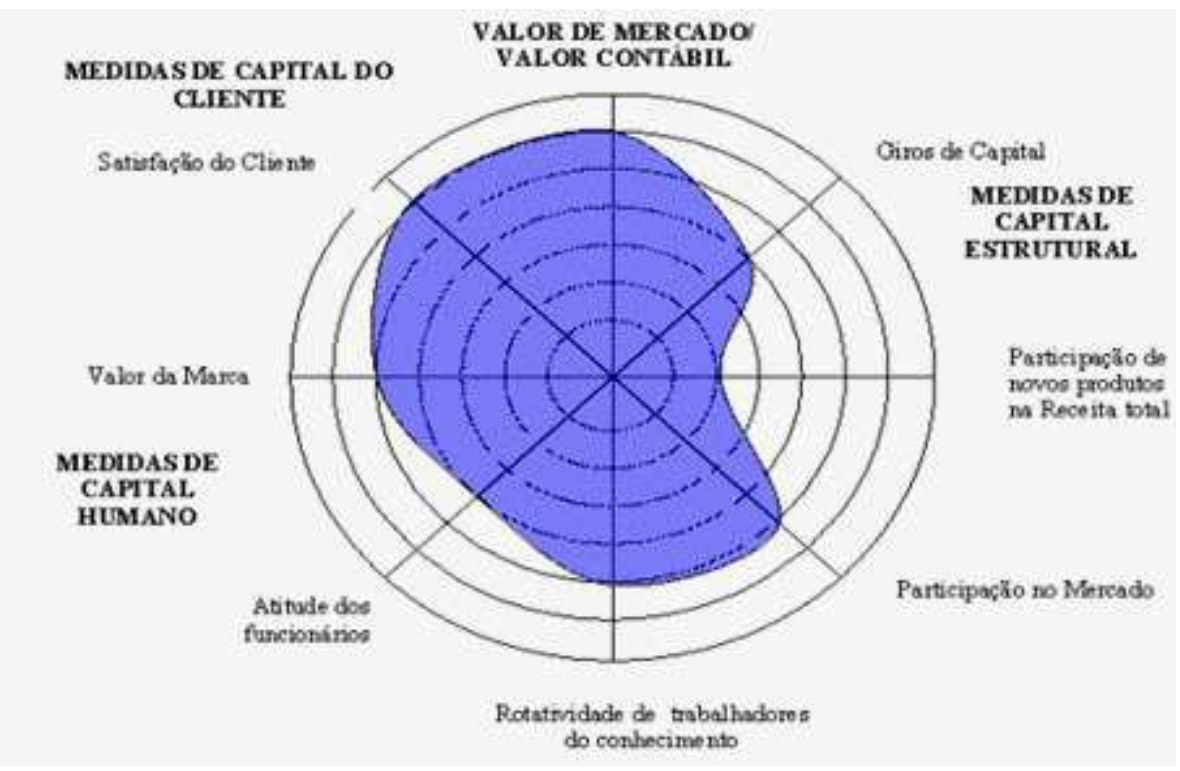

Figura 05 - Navegador do Capital Intelectual

Fonte: STEWART (1997)

O navegador não se propõe a exibir valores, mas definir as escalas de maneira que as metas sejam alocadas às extremidades, onde o eixo cruza o círculo. Traçando-se a posição em cada escala e ligando os pontos, obtém-se um polígono, mostrando no interior os resultados atuais e na parte externa o que se deseja.

\subsection{MODELO DE SVEIBY}

Sveiby (1998, p. 233) justificando a criação de um modelo de avaliação para o ativo intangível, menciona que:

"Indicadores-chave" alternativos oferecem novos e interessantes ângulos e são de grande valor para investidores e gerentes. Desde a década de 1950, e mesmo antes, as empresas calculam alguns indicadores não-monetários para corroborar os estudos sobre eficiência, mas nunca divulgam em seus relatórios anuais.

O referido autor cita que as principais razões para a não mensuração e divulgação dos ativos intangíveis, nos relatórios das empresas são a de que, primeiro muitos gerentes consideram essas informações inúteis, em segundo lugar, o receio de que os indicadores não 
financeiros traduzam informações por mais reveladores de suas estratégias para o mercado e finalmente não existe um modelo teórico rigoroso para esse tipo de relatório (avaliação de capital intelectual).

O modelo Sveiby - observa-se que é pedagogicamente produtivo estabelecer os seguintes passos para a construção deste modelo:

- Estabelecer as finalidades das avaliações - o autor determina os aspectos mais relevantes, partindo de duas orientações: o ambiente interno, gerando informações para os dirigentes, e o ambiente externo, gerando informações para os clientes, credores, acionistas e investidores.

- Classificar os diversos grupos de funcionários das categorias - o autor sugere uma classificação dos funcionários em profissional (as pessoas que pensam e dão condução à organização) e o pessoal de suporte (que auxiliam os profissionais).

- Determinar os componentes dos ativos intangíveis - Os ativos invisíveis no balanço patrimonial de uma organização podem ser classificados como um grupo de três elementos juntamente com os ativos materiais ou visíveis que integram o balanço patrimonial como mostra a figura a seguir:

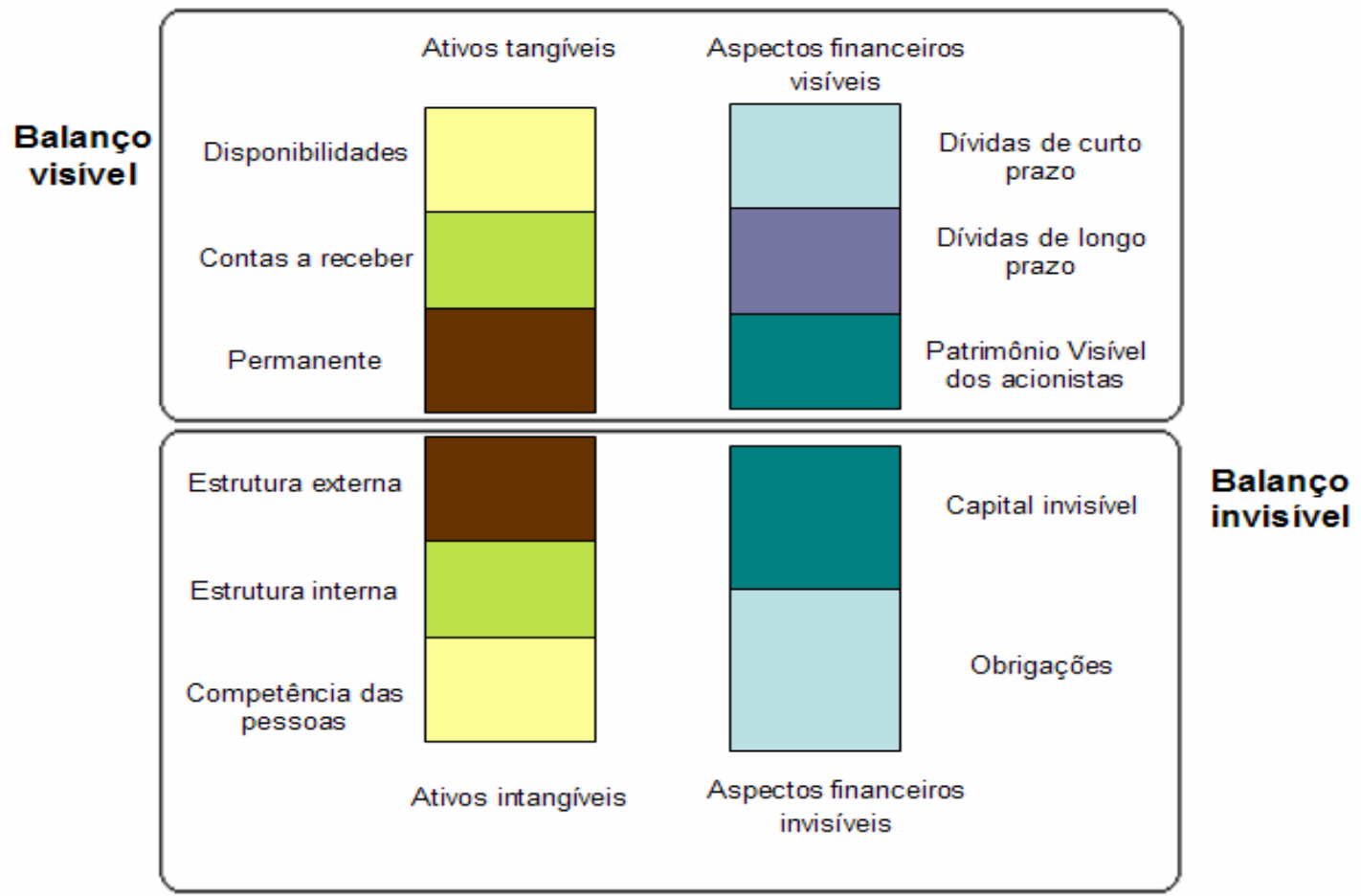

Quadro 6 - Balanço Patrimonial de uma Organização de Conhecimento

Fonte: SVEIBY (1998)

Conforme quadro 6, os intangíveis podem ser classificados dentro de três grupos:

Competência do Funcionário - inclui-se a capacidade dos funcionários, a rentabilidade no serviço executado, escolaridade, experiência e como processar ou apresentar a criação tanto de bens tangíveis como intangíveis.

Estrutura interna - incluem patentes, conceitos, modelos e sistemas administrativos, cultura e espírito organizacional. Para esta avaliação, também são usados os indicadores de crescimento/renovação, eficiência e estabilidade. 
- Crescimento/renovação: envolve investimentos na estrutura interna e investimentos em sistemas de processamentos de informações. O crescimento e renovação para a estrutura interna indicam o quanto à empresa está preparado (ou se preparando) para o futuro no tocante as suas condições de infra-estrutura.

- Eficiência: envolve a proporção de pessoal de suporte e as vendas por funcionários. Trata-se de um indicador da presença e contribuição destes funcionários para os resultados do negócio.

- Estabilidade: envolve os pontos referentes à idade da organização, rotatividade do pessoal de suporte e taxa de novatos. A estabilidade do pessoal de suporte é um indicador do tempo destes na empresa. O ideal seria a presença de índices medianos, pois uma alta taxa de estabilidade poderia indicar que a organização é conservadora, e o contrário, indicaria um alto índice de insatisfação na empresa.

Estrutura externa - Esta estrutura inclui marcas, imagem, relacionamento com fornecedores e com clientes. Também pode ser avaliada segundo os fatores de crescimento/renovação, de eficiência e de estabilidade.

- Crescimento/renovação: refere-se à lucratividade por clientes e ao número de clientes atendidos no ano. Indica o propósito mais básico do relacionamento com o cliente, ou seja, o número e a lucratividade deles. O ideal é que os resultados sejam maximizados.

- Eficiência: Mede o índice de clientes satisfeitos e as vendas por cliente. Indica o nível de satisfação e contribuição dos clientes para os resultados do negócio. O ideal é que os resultados de uma empresa acompanhassem os índices das melhores empresas.

- Estabilidade: Indica a proporção de grandes clientes, estrutura etária e freqüência da repetição de pedidos. Juntos, estes fatores indicam o tempo dos clientes na empresa. Neste caso, o ideal seria a maximização do resultado.

Portanto conforme demonstrado verifica-se como vantagem do modelo apresentado por Sveiby, para a possibilidade de mensuração do Capital Intelectual, ser simples e de fácil interpretação, porém limitado no aspecto financeiro, devido a utilização de indicadores nãofinanceiros.

\subsection{DIFERENÇA ENTRE O VALOR DE MERCADO E O VALOR CONTÁBIL}

De acordo com Góis (2000, p.105-110), calcular a diferença entre o valor de mercado e o valor contábil é uma das formas mais utilizadas para mensurar o capital intelectual. Nele as Demonstrações Contábeis Auditadas são a base. O valor do capital intelectual de uma empresa é determinado pela diferença entre valor contábil e valor de mercado (valor unitário de ação x $n^{\circ}$ de ações) de uma empresa. Como o valor contábil do capital próprio é o residual nos ativos depois de pagos todos os passivos, a diferença entre o valor contábil e o valor de mercado se destina a remunerar o valor dos ativos intangíveis, isto é, o capital intelectual A simplicidade característica do modelo talvez se constitua na maior virtude, já que, se o valor de mercado de uma empresa é maior que o valor contábil, faz sentido atribuir a diferença ao capital intelectual.

\subsection{RAZÃO ENTRE O VALOR DE MERCADO E O VALOR CONTÁBIL (OU MARKET TO BOOK)}


Utilizar a razão entre o valor de mercado e o valor contábil (ou market to book), é uma medida foi apresentada pela primeira vez por Kaldor, em 1966 (Art.Considerações acerca dos métodos de avaliação do capital intelectual, $\left.\mathrm{RBC} \mathrm{n}^{\circ} 137, \mathrm{p} .30\right)$. Lev (p.29, 2002) registra que o valor Market-to-Book (também conhecido como razão M/B) é o resultante da divisão do valor de mercado das empresas pelo valor de seus ativos líquidos (somatório dos bens e direitos subtraídos das obrigações com terceiros, ou seja, o patrimônio líquido) conforme constam de seus balanços patrimoniais.

\section{7. “Q” DE TOBIN}

Proposto originalmente por Tobin \& Brainard, o quociente que viria a ser conhecido como "Q" de Tobin é definido, segundo Fama \& Barros (RBC no 137, p.30, 2002), como a relação entre o valor de mercado de uma empresa e o valor de reposição de seus ativos físicos. Assim, ele representa a razão entre dois valores atribuídos ao mesmo conjunto de ativos, ou seja, relaciona-se com a definição de valor de reposição dos ativos em lugar de seu valor contábil.

Estes fatores confirmam que a utilização de alguns modelos de mensuração do Capital Intelectual deixa evidente a existência dos valores "ocultos" na organização, e que esses precisam ser mensurados. O importante é verificar se o modelo aplicado está adaptado aos objetivos estratégicos da organização, permitindo que ela possa reagir favoravelmente às mudanças cada vez mais frequentes no ambiente de mercado em que atua.

Finaliza-se o estudo apresentado uma tabela comparando os modelos, destacando as semelhanças e diferenças encontradas nos modelos citados. 
POSSIBILIDADES DE MENSURAÇÃO DO CAPITAL INTELECTUAL

\begin{tabular}{|c|c|c|c|c|c|}
\hline Método & VANTAGENS & LIMITAÇ̄̃ES & FORMA USADA & $\begin{array}{c}\text { ENFASE } \\
\text { FINANCEIRA }\end{array}$ & $\begin{array}{l}\text { PERSPECTIVAS } \\
\text { ADOTADAS }\end{array}$ \\
\hline $\begin{array}{c}\text { Diferença } \\
\text { entre Valor } \\
\text { mercado do } \\
\text { Valor Contábil }\end{array}$ & $\begin{array}{l}\text { Simplicidade } \\
\text { de utilizaçẫo }\end{array}$ & $\begin{array}{c}\text { Frágil perante } \\
\text { influências do } \\
\text { mercado }\end{array}$ & $\begin{array}{l}\text { Equaçẫo } \\
\text { matemática }\end{array}$ & Total & $\begin{array}{c}\text { Única } \\
\text { (financeira) }\end{array}$ \\
\hline $\begin{array}{l}\text { Market-to- } \\
\text { book }\end{array}$ & $\begin{array}{c}\text { Cálculo simples. } \\
\text { Comparável com } \\
\text { o tempo. }\end{array}$ & $\begin{array}{l}\text { Influênciável por } \\
\text { oscilaçốes de } \\
\text { fatores externos. }\end{array}$ & $\begin{array}{l}\text { Equação } \\
\text { matemática }\end{array}$ & Total & $\begin{array}{c}\text { Única } \\
\text { (financeira) }\end{array}$ \\
\hline $\begin{array}{l}\text { "Q" de } \\
\text { Tobin }\end{array}$ & $\begin{array}{l}\text { Considera o custo } \\
\text { de reposiçâao de } \\
\text { ativos. Fácil } \\
\text { interpretaçăo. } \\
\end{array}$ & $\begin{array}{c}\text { Afetado pelos efeitos } \\
\text { do mercado. }\end{array}$ & $\begin{array}{l}\text { Equaçẫo } \\
\text { matemática }\end{array}$ & Total & $\begin{array}{c}\text { Única } \\
\text { (financeira) }\end{array}$ \\
\hline $\begin{array}{l}\text { Stewart - } \\
\text { Navegador } \\
\text { do Capital } \\
\text { Intelectual }\end{array}$ & $\begin{array}{c}\text { Fácil visualizaçẫo. } \\
\text { Acompanhamento } \\
\text { do desenvolvimento } \\
\text { de vários } \\
\text { indicadores ao } \\
\text { mesmo tempo. }\end{array}$ & $\begin{array}{l}\text { Dificuldade na } \\
\text { determinaçẩo dos } \\
\text { indicadores de } \\
\text { desempenho. }\end{array}$ & $\begin{array}{l}\text { Gráfico } \\
\text { radar. }\end{array}$ & Parcial & $\begin{array}{c}\text { Diversas, a serem } \\
\text { estipuladas pelos } \\
\text { usuários }\end{array}$ \\
\hline $\begin{array}{l}\text { Skandia - } \\
\text { Edvinsson } \\
\text { e Malone }\end{array}$ & $\begin{array}{c}\text { Fornece uma } \\
\text { perspectiva geral } \\
\text { do passado e do } \\
\text { futuro da empresa. }\end{array}$ & $\begin{array}{c}\text { Elaboraçẫo } \\
\text { complexa. } \\
\text { Subjetivadade. }\end{array}$ & $\begin{array}{c}\text { Matriz } \\
\text { e equaçẫo } \\
\text { matemática }\end{array}$ & Parcial & $\begin{array}{l}\text { Diversas (clientes, } \\
\text { processos, humana, } \\
\text { financeira e de } \\
\text { renovaçẫo). }\end{array}$ \\
\hline Sveiby & $\begin{array}{l}\text { Apresentaçẫo } \\
\text { simples. } \\
\text { Fácil interpretaçẫo. }\end{array}$ & $\begin{array}{c}\text { Escolha dos } \\
\text { indicadores } \\
\text { complexa. }\end{array}$ & $\begin{array}{c}\text { Matriz } \\
\text { de indicadores. }\end{array}$ & Nenhuma & $\begin{array}{l}\text { Diversas (estrutura, } \\
\text { externa, estrutura } \\
\text { interna, competência } \\
\text { das pessoas). }\end{array}$ \\
\hline
\end{tabular}

Quadro 1 - Possibilidades Mensuração Capital Intelectual

Fonte: Wernke, 2001.

Dentro desse contexto, conforme autor, os modelos apresentados tradicionais "Diferença entre valor de mercado a valor contábil", "Market-to-book" e "Q de Tobin", apresentam ênfase financeira total, porém suas perspectivas de mercado adotadas são unicamente financeiras.

Quanto aos modelos de "Stewart", "Edvinsson e Malone" e "Sveiby" possuem no primeiro e segundo uma ênfase financeira parcial, já o terceiro nenhuma ênfase financeira, no entanto suas perspectivas são boas, pois abordam estrutura interna e externa, competências das pessoas e outras a serem estipuladas pelos usuários.

\section{CONSIDERAÇÕES FINAIS}

Conforme as referências bibliográficas, pode-se observar que os autores destacam a necessidade da quantificação e inclusão nos relatórios contábeis e financeiros do capital intelectual, para que a Contabilidade atenda de fato a sua função de fornecer suporte para a tomada de decisão, porém consideram que esta quantificação e inclusão é difícil e subjetiva. 
Devido a esta subjetividade, o capital intelectual representa um desafio para as empresas.Parece pacífico que se trata de um ato intangível, contudo à semelhança dos restantes intangíveis trata-se de um valor de difícil definição e mensuração. No entanto a avaliação do capital intelectual constitui um fator chave em todo este processo, pois o valor deste ativo só poderá ser gerido se tiver sido mensurado. Não se pode gerir um ativo que não seja identificado e conhecido pela empresa.

Os diversos modelos estudados demonstraram particularidades, onde foram elencados fatores como vantagens, limitações à forma utilizada de apresentação ou obtenção, a importância ou ênfase dada ao aspecto financeiro e, ainda, as perspectivas usadas em cada modelo.

Finalmente, constata-se que diante do elevado grau de subjetividade dos modelos propostos, talvez não seja fácil a escolha de um entre eles para definir-se como modelo padrão para a mensuração do capital intelectual para qualquer tipo de organização, e sim utilizá-los como fonte de pesquisa, em busca de modelo aceito universalmente como ferramenta de mensuração do capital intelectual.

Contudo, as essências dos modelos não devem variar muito em relação aos modelos de Sveiby, Stewart e de Edvinsson e Malone. Observa-se que há necessidade destes procedimentos serem aperfeiçoados para se obter regras mais harmônicas entre as empresas, possibilitando maior transparência e segurança não apenas para os investidores, mas para o mercado em geral. 


\section{REFERÊNCIAS}

ANTUNES, Maria Thereza Pompa. Capital Intelectual. Editora Atlas, 2000.

BARRETO, Maria da Graça Pitiá; LEONE,George Guerra; BARRETO Eduardo Fausto; TEIXEIRA, Anselmo Montes. A Difícil Mensuração do Capital Intelectual. Disponível em:

$<$ http://www.abcustos.org.br/texto/viewpublic?ID_TEXTO=1664> acesso em 06 nov. 2011, 21:00:35.

BEUREN, Ilse Maria; COLAUTO, Romualdo Douglas. Avaliação do Capital Intelectual na perspectiva da tridimensionalidade da linguem contábil. Revista de Administração e Contabilidade da Unisinos ISSN: 1807-054 ed: v.2 fasc. 2 p. 85 - 101, 2005

BROOKING, Annie. Intellectual capital: core asset for the third Millennium enterprise. Boston: Thomson Publishing Inc., 1996.

CAMARGO, Imara Hebling Camargo. Ativos Intangíveis. Disponível em: $<$ http://www.administradores.com.br/informe-se/artigos/ativos-intangiveis/54374> acesso em 10 jun. 2011, 19:00:25.

CAVALCANTE, Paulo Roberto Nóbrega; NETO, Cícero Caldas; ANDRADE, Geraldo Magela de. Capital Intelectual e Goodwill: Ativo Intangíveis de Difícil Mensuração. Disponível em:

<http://www.atena.org.br/revista/ojs2.2.306/index.php/pensarcontabil/article/viewFile/21/21 > acesso em: 02 nov. 2011, 19:19:34

COMITÊ DE PRONUNCIAMENTOS CONTÁBEIS. Pronunciamento Técnico CPC 04 (R1) Ativo intangível. R1, de 05 de novembro de 2010. Disponível em: <www.cpc.org.br>. Acesso em: 01 ago. 2011.

DRUCKER, Peter F. Administrando em tempos de grandes mudanças. 4 ed. Trad. Nivaldo Montigelli. São Paulo: Pioneira, 1997

EDVINSSON L., MALONE, M.S. Capital Intelectual. Trad. Roberto Galman. São Paulo: Makron Books, 1998.

FREIRE, J. de Andrade. Capital Intelectual - Um estudo comparativo entre as diversas metodologias de mensuração encontradas na literatura. Disponível em: <http://m.classecontabil.com.br/artigos/exibir/699 > acesso em 06 nov. 2011, 20:00:15.

GALLON, Alessandra Vasconcelos; NASCIMENTO Sabrina do; ENSSLIN Sandra Rolim. Disponível em: <http://www.abcustos.org.br/texto/viewpublic?ID_TEXTO=2766 > acesso ; em 07 nov. 2011, 23:40:55.

GALVÃO, Barbara de Souza; COSENZA, José Paulo. Considerações sobre a Evidenciação de Ativos Intangíveis no Contexto Brasileiro: Estudo de Caso Perdigão S/A. Disponível em: http://www.atena.org.br/revista/ojs-2.2.3-06/index.php/pensarcontabil/article/view/115 acesso em 13 nov. 2011, 12:15: 45. 
GÓIS, Cristina Gonçalves. Capital Intelectual: O Intangível do Século XXI. Disponível em: $<$ http://www.abcustos.org.br/texto/viewpublic?ID_TEXTO=763 > acesso em 07 nov. 2011, 23:50:10.

GRUPO SKANDIA. Visualizando o capital intelectual na Skandia. Suplemento do Relatório Anual. Estocolmo, 1994

HOLANDA, Lucianno Moreira C. de; FILHO, Joel Freire Silva; ROCHA, Ricardo Campos da. Capital Intelectual: Um Estudo de Caso Numa Empresa de Jornalismo. Disponível em: <http://revista.feb.unesp.br/index.php/gepros/article/viewArticle/134 > acesso em 02 de Nov. 2011, 19:28:00.

MELLO, Itamara de. Capital Intelectual: Patrimônio Intangível das Organizações. Disponível em: <http://www.administradores.com.br/informe-se/artigos/capital-intelectual-patrimoniointangivel-das-organizacoes/52909/ > acesso em 10 jun. 2011, 19:00:25.

MELO, Paulo da Silva. Técnicas de Avaliação de Empresas: Um estudo visando à mensuração dos Ativos Intangíveis em empresas industriais do setor eletroeletrônico. Dissertação de Mestrado, São Paulo, 2009.

MENDONÇA, Lilian dos Anjos. O Desafio da Contabilidade na Evidenciação e Registro do Capital Intelectual frente às exigências da Lei $\mathrm{n}^{\circ} 11.638 / 2007$. Disponível em: $<$ http://intertemas.unitoledo.br/revista/index.php/ETIC/article/viewFile/2118/2325 > acesso em 30 out. 2011, 00:31:02.

MONOBE, Massanori. Contribuição à mensuração e contabilização do goodwill adquirido. Tese (Doutorado) - Faculdade de Economia, Administração e Contabilidade. São Paulo : Universidade de São Paulo, 1986.

REHBEIN, Airton Roberto; METTE Priscilla (UNILASALLE). Disponível em:

http://www.abcustos.org.br/texto/viewpublic?ID_TEXTO=2551 acesso em 20 nov. 2011, 21:00:15.

SANTOS, José Luiz dos; SCHMIDT Paulo; MACHADO, Nilson Perinazzo; FERNANDES, Luciane Alves; PINHEIRO, Paulo Roberto. Disponível em: <http://www.abcustos.org.br/texto/viewpublic?ID_TEXTO=1672 > acesso em 19 nov. 2011, 22:35:12.

SILVA, Pedro Ylunga Costa da; TROMBELLI, Renata Oliveira; CURVA, Jazmin Figari de La (UEM). Investigação e análise do perfil da produção científica brasileira em contabilidade voltada para o capital intelectual. Disponível em: <http://www.abcustos.org.br/texto/viewpublic?ID_TEXTO=3176> acesso em 20 nov. 2011, 21:00:15.

SOUZA, Luis Henrique Lenke de; CALDAS, Marco Aurélio; MACEDO, M.A.S. . As Organizações e a Mensuração do Capital Intelectual. Disponível em: <http://www.aedb.br/seget/artigos05/375_Artigo\%20\%20Lenke,\%20Caldas\%20e\%20Maced o.pdf > acesso em 03 nov. 2011, 23:13:35.

STEWART, Thomas A. Your company's most valuable asset: intellectual capital. Fortune, p. 28-33, 3 Oct. 1994. 
VEIBY, K.E., Nova Riqueza das Organizações: Patrimônio de Conhecimento, A, Campus.

WERNKE, R.; LEMBECK, M. Mensuração de intangíveis. Revista Brasileira de Contabilidade. 2001. 